\title{
Contrasting physical and chemical conditions of two springs fed by active rock glaciers
}

\author{
Stefano Brighenti ${ }^{1}$, Michael Engel ${ }^{2}$, Monica Tolotti $^{3}$, Maria Bruno ${ }^{3}$, Geraldene Wharton ${ }^{4}$, \\ Francesco Comiti $^{1}$, Werner Tirler ${ }^{5}$, and Walter Bertoldi ${ }^{6}$ \\ ${ }^{1}$ Free University of Bozen-Bolzano \\ ${ }^{2}$ Bundesanstalt für Gewässerkunde \\ ${ }^{3}$ Edmund Mach Foundation Research and Innovation Centre \\ ${ }^{4}$ Queen Mary University of London \\ ${ }^{5}$ Eco Research Srl \\ ${ }^{6}$ Università degli Studi di Trento
}

December 23, 2020

\begin{abstract}
Rock glaciers are increasingly influencing the hydrology and water chemistry of Alpine catchments, with important implications for drinking water quality and ecosystem health under a changing climate. During summers of 2017 - 2019, we monitored the physical and chemical conditions of springs emerging from two active rock glaciers (ZRG and SRG) with distinct geomorphological settings in the Eastern Italian Alps (Solda/Sulden catchment). Both springs had constantly cold waters $\left(1.4 \pm 0.1^{\circ} \mathrm{C}\right)$, and their ionic composition was dominated by SO42-, HCO3-, Ca2+ and Mg2+. Concentrations of major ions and trace elements, and values of water isotopes $(\delta 18 \mathrm{O}, \delta 2 \mathrm{H})$, increased towards autumn with an asymptotic trend at SRG, and a positive unimodal pattern at ZRG, where concentrations peaked 60 - 80 days after the end of the snowmelt. Wavelet analysis on electrical conductivity (EC) and water temperature records revealed daily cycles only at SRG, and significant weekly/biweekly fluctuations at both springs attributable to oscillations of meteorological conditions. Several rainfall events triggered a transient ( $0.5-2 \mathrm{hrs})$ EC drop and water temperature rise (dilution and warming) at SRG, whereas only intense rainfall events occasionally increased EC at ZRG (solute enrichment and thermal buffering), with a long-lasting effect ( 6 - $48 \mathrm{hrs}$ ). Our results, supported by a limited but emerging literature, suggest that: i) the distinctive composition of the bedrock drives different concentrations of major ions and trace elements in rock glacier springs; ii) pond-like and stream-like springs have distinct fluctuations of water parameters at different timescales; iii) peaks of EC/solute concentrations indicate a seasonal window of major permafrost thaw for rock glaciers feeding pond-like springs. These results provide a first quantitative description of the hydrological seasonality in rock glacier outflows, and their hydrochemical response to precipitation events, bringing relevant information for water management in the European Alps under climate change.
\end{abstract}

\section{Hosted file}

Brighentietal_final.pdf available at https://authorea.com/users/384712/articles/500266contrasting-physical-and-chemical-conditions-of-two-springs-fed-by-active-rock-glaciers 

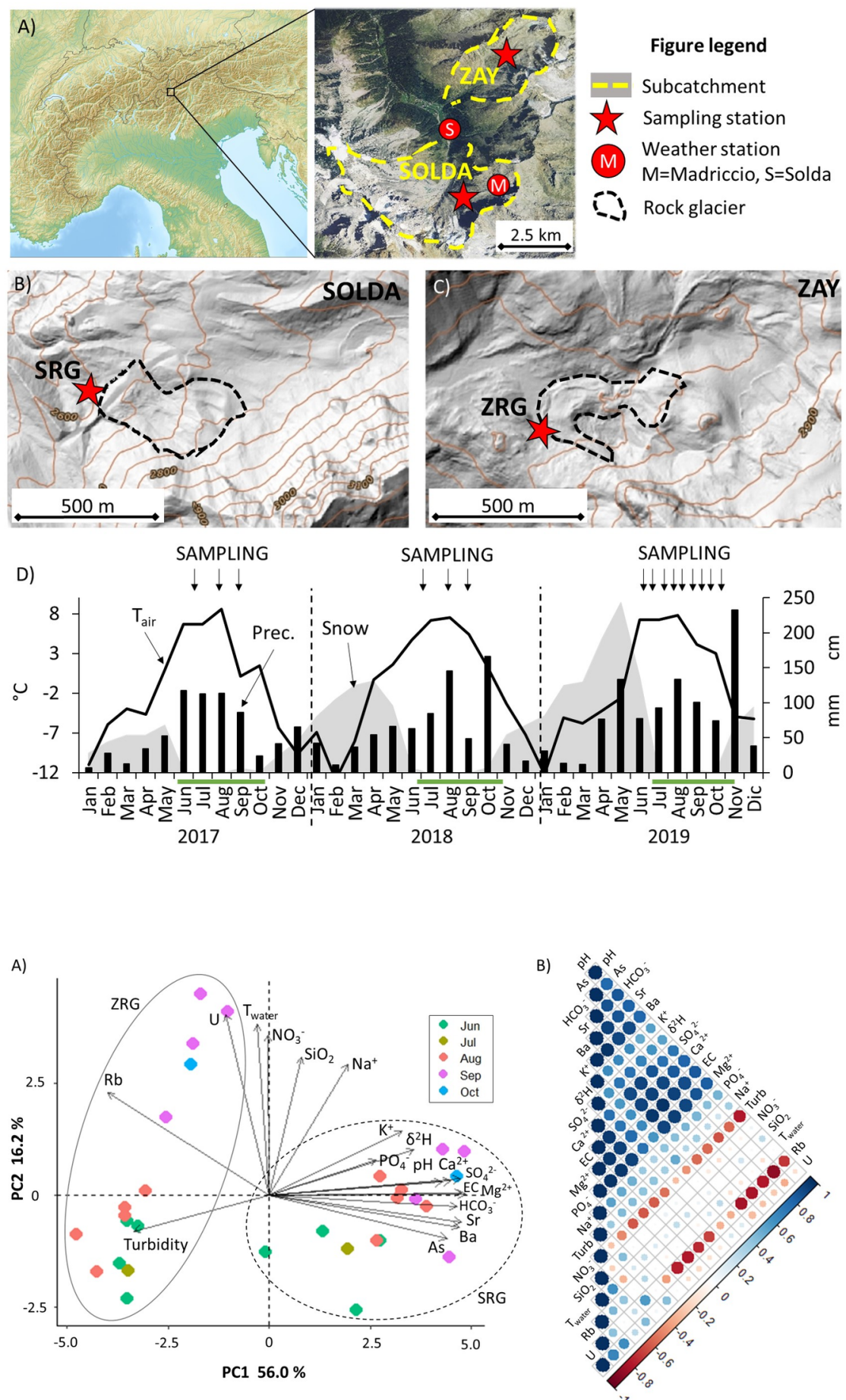


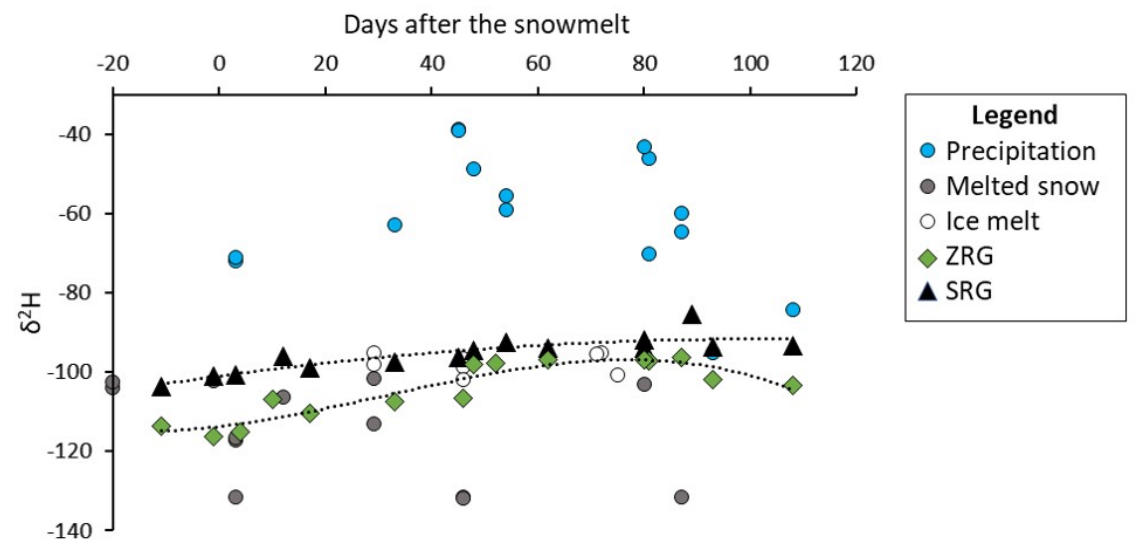

SRG

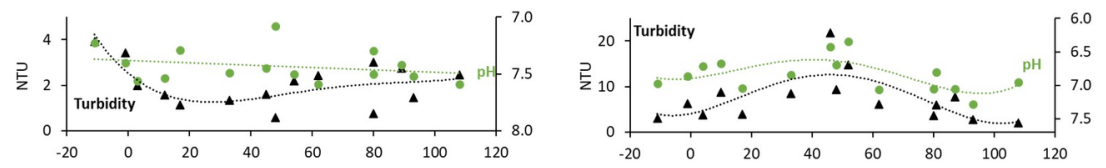

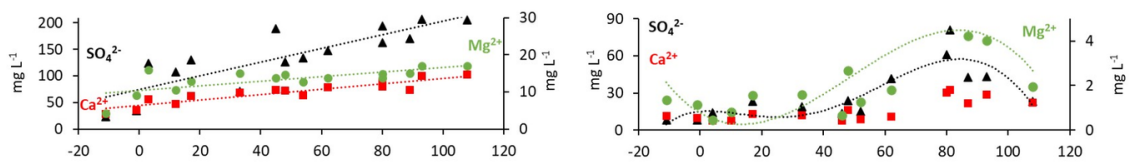
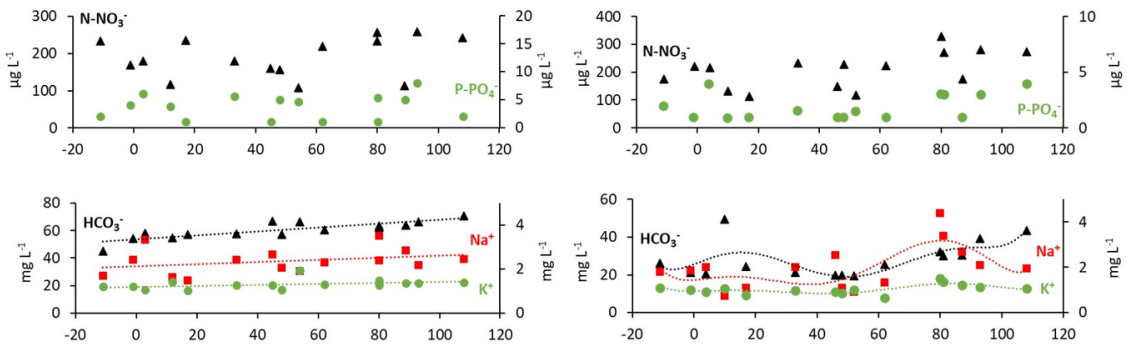

Days after the snowmelt 

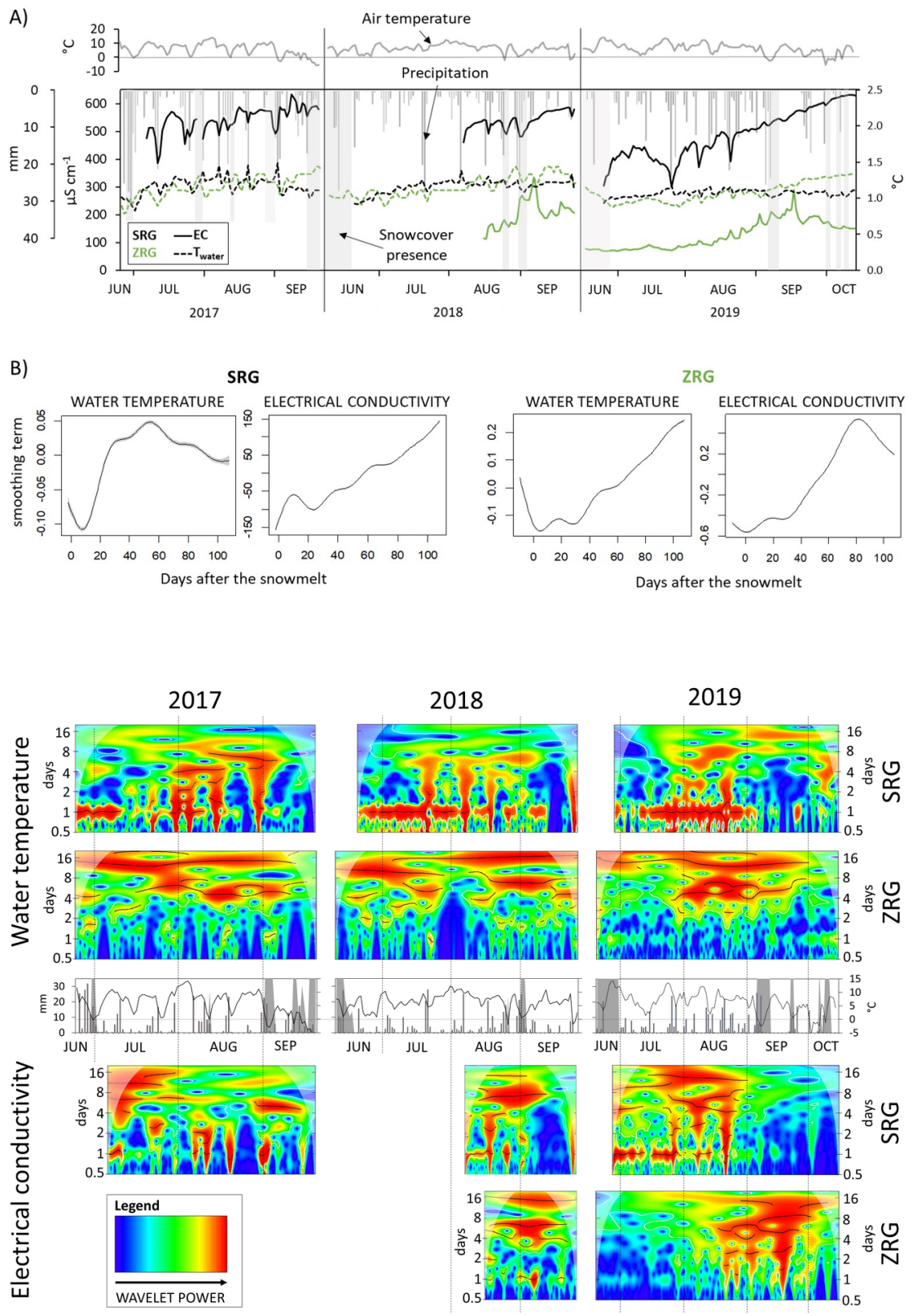

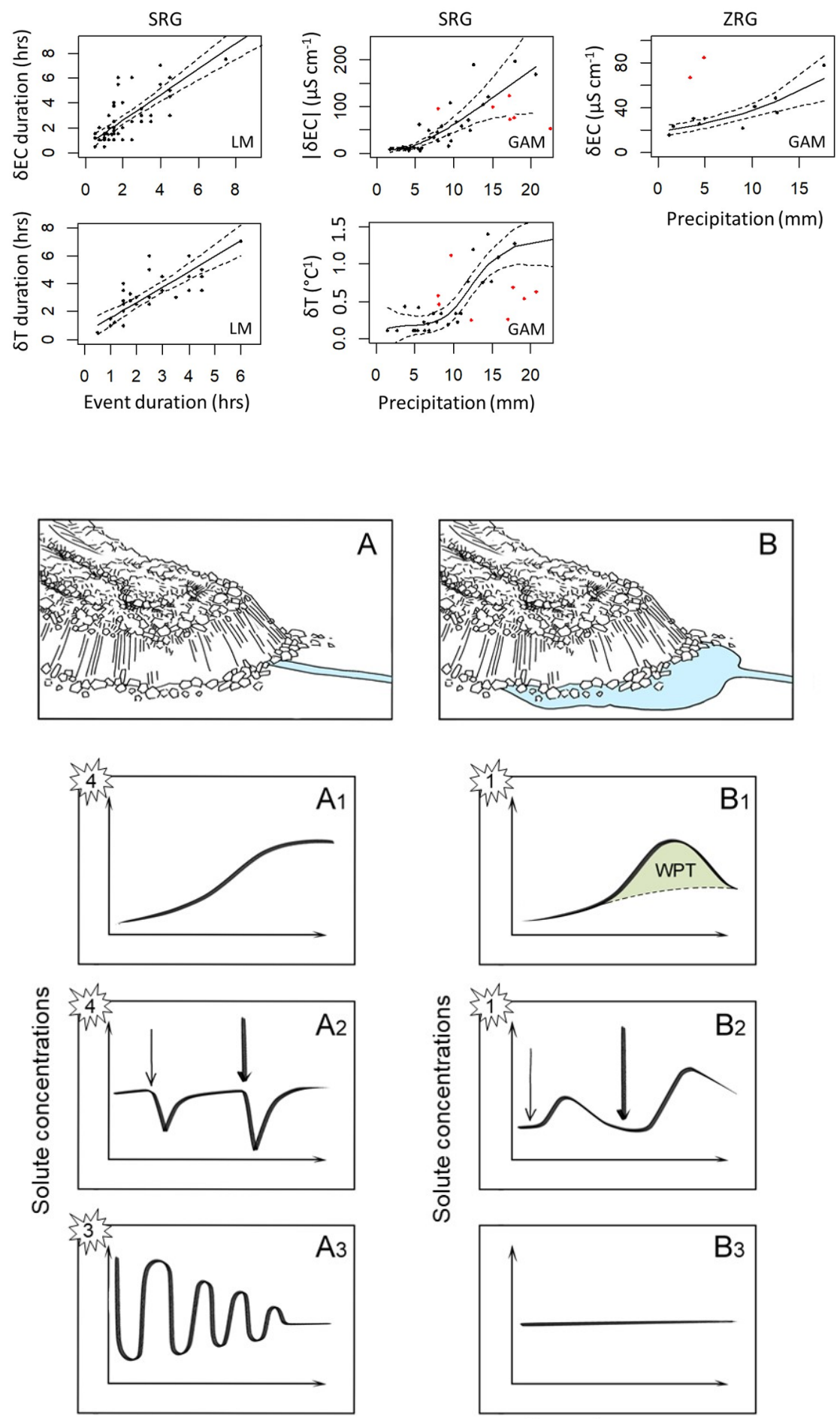

Snow free season
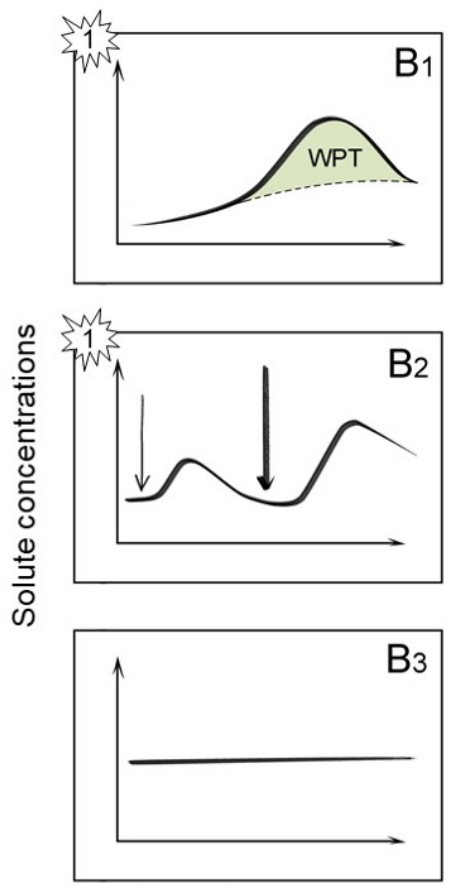

Snow free season

Hosted file

Table 1.pdf available at https://authorea.com/users/384712/articles/500266-contrasting- 
physical-and-chemical-conditions-of-two-springs-fed-by-active-rock-glaciers

\section{Hosted file}

Table 2.pdf available at https://authorea.com/users/384712/articles/500266-contrastingphysical-and-chemical-conditions-of-two-springs-fed-by-active-rock-glaciers

Hosted file

Table 3.pdf available at https://authorea.com/users/384712/articles/500266-contrastingphysical-and-chemical-conditions-of-two-springs-fed-by-active-rock-glaciers 